\title{
Memahami Organisasi Free West Papua Campaign Melalui Kampanye Dukungan Terhadap United Liberation Movement for West Papua (ULMWP) Tergabung Dalam Melanesian Spearhead Group (MSG)
}

\author{
M. Yusuf Samad ${ }^{1, *}$, Diah Ayu Permatasari $^{2}$ \\ ${ }^{1}$ Asosiasi Peneliti Jaringan Sosial Indonesia (APJARSI); Jl. Haji Ali, No. 77, Kramat Jati, \\ Jakarta Timur; e-mail: ahmadyusad@gmail.com. \\ ${ }^{2}$ Fakultas IImu Komunikasi; Universitas Bhayangkara Jakarta Raya; Jl. Harsono RM No.67 \\ Ragunan, Pasar Minggu, Jakarta Selatan; e-mail: pepy@ubharajaya.ac.id. \\ * Korespondensi: e-mail: ahmadyusad@gmail.com \\ Submitted: 02/11/2021; Revised: 18/11/2021; Accepted: 21/11/2021; Published: $31 / 12 / 2021$
}

\begin{abstract}
The Free West Papua Campaign is an organization that massively campaigns on social media Twitter and its website to garner support from the international community regarding Papuan independence, one of its efforts is to conduct campaigns in cyberspace with a narrative supporting the United Liberation Movement for West Papua (ULMWP) to become full member of the subregional organization MSGin the hope that this membership status can strengthen ULMWP's political maneuvering in bringing the issue of an independent Papua to the international level. The purpose of this study was to find out how the campaign carried out by the Twitter account @FreeWestPapua and how other Twitter users responded to the campaign. The research used is a qualitative research by juxtaposing the study of literature with data from social media Twitter and the freewestpapua.org. The results show that the Free West Papua Campaign uses ideologically or cause oriented campaigns and uses a campaign model in the form of a componential campaign. The response from Twitter users is more dominated by following instructions on hashtags rather than the message they want to convey.
\end{abstract}

Keywords: Campaign, Free West Papua Campaign, Melanesia Spearhead Group, ULMWP

\begin{abstract}
Abstrak
Free West Papua Campaign merupakan organisasi yang secara masif melakukan kampanye di media sosial Twitter dan situs webnya untuk menggalang dukungan dari masyarakat internasional terkait kemerdekaan Papua, salah satu upayanya adalah melakukan kampanye di ruang siber dengan narasi mendukung United Liberation Movement for West Papua (ULMWP) menjadi anggota penuh organisasi subregional MSG dengan harapan status keanggotaan tersebut dapat memperkuat manuver politik ULMWP dalam membawa isu Papua merdeka dalam tataran internasional. Tujuan penelitian ini untuk mengetahui bagaimana kampanye yang dilakukan oleh akun Twitter @FreeWestPapua dan bagaimana respons pengguna Twitter lainnya terhadap kampanye tersebut. Penelitian yang menggunakan pendekatan kualitatif dengan menyandingkan antara studi literatur dengan data-data dari media sosial Twitter dan situs web freewestpapua.org. Hasil penelitian menunjukkan bahwa Free West Papua Campaign menggunakan kampanye jenis ideologically or cause oriented campaigns dan menggunakan model kampanye berupa komponensial kampanye. Adapun respons dari pengguna Twitter lebih didominasi mengikuti instruksi tentang tagar daripada pesan yang ingin disampaikan.
\end{abstract}

Kata kunci: Kampanye, Free West Papua Campaign, Melanesia Spearhead Group, ULMWP 


\section{Pendahuluan}

Dalam situs web resmi Pemerintah Provinsi Papua, disebutkan bahwa posisi Papua berada di pulau West New Guinea atau Nugini bagian barat. Papua juga kerap kali disebut sebagai Papua Barat dengan perpektif seluruh pulau Nugini termasuk belahan timur negara tetangga, Papua Nugini atau East New Guinea. Papua Barat adalah istilah yang sering digunakan oleh kelompok separatis Papua yang ingin membentuk negara sendiri (Pemerintah Provinsi Papua, n.d.). Istilah itu juga digunakan oleh tokoh dan/atau kelompok separatis dalam melakukan kampanye di media sosial Twitter, seperti Ketua United Liberation Movement for West Papua (ULMWP) sekaligus pendiri organisasi sukarelawan Free West Papua Campaign, Benny Wenda.

Di tahun 2021, organisasi tersebut melakukan kampanye di ruang siber untuk mencari dukungan dari warganet di berbagai negara agar ULMWP menjadi Full Member atau anggota penuh dalam Melanesia Spearhead Group (MSG). MSG merupakan organisasi sub regional dan hasil kesepakatan negara-negara di Melanesia yang tujuan awalnya untuk membentuk suatu komunitas yang berkaitan dengan ekonomi, perdagangan dan pembangunan. (Amran, 2017).

Berdasarkan situs web frewestpapua.org, kampanye ULMWP tergabung dalam MSG dilakukan agar ULMWP menjadi anggota penuh dalam MSG. Status keanggotaan penuh tersebut akan menjadi langkah pencapaian paling signifikan untuk pengakuan resmi orang Papua Barat sebagai orang Melanesia. Selain itu, sebuah langkah atau ketetapan yang secara resmi akan menegasi atau membantah hak Indonesia untuk menduduki wilayah Papua Barat dalam level diplomasi yang lebih tinggi (Free West Papua Campaign, n.d.)

Status keanggotaan dalam MSG terdiri dari tiga jenis, yaitu Pengamat (Observer), Anggota Asosiasi (Associate Member), dan Anggota Penuh (Full Member). Hasil pertemuan tertinggi di MSG berupa MSG Leaders' Summit (KTT) ke-20 yang dilakuan di Kepulauan Solomon, tepatnya di Honiora pada 24 hingga 26 Juni 2015 lalu, menyatakan bahwa status Indonesia mengalami peningkatan dari yang tadinya sebagai observer, kini menjadi Associate Member. Peningkatan status Indonesia di MSG disebabkan MSG ingin menjalin hubungan kerja sama antara Indonesia dengan negara anggota MSG. Sedangkan status keanggotaan ULMWP di MSG adalah Observer yang status keanggotaannya lebih dari Associate Member yang keterlibatannya dalam MSG cukup terbatas (Ramadhan, 2018). Sebelumnya, pada tahun 2016 lalu, MSG telah menolak ULMWP dijadikan sebagai anggota penuh pada MSG, penolakan tersebut disampaikan melalui KTT Khusus MSG di Kepulauan Solomon (Samosir, 2016).

Pada dasarnya, KTT MSG digelar setiap dua tahun sekali. Namun, jika ada isu yang dianggap penting untuk dibahas oleh anggota penuh MSG, maka KTT Khusus MSG dapat digelar dalam rentan waktu dua tahun tersebut. (Direktorat Kerja Sama Intrakawasan dan Antarkawasan Asia Pasifik dan Afrika, 2019). Pada 28 April tahun 2021, rangkaian KTT telah dilaksanakan dengan agenda tentang anggaran pada kegiatan Senior Official Meeting (SOM) yang diikuti oleh pemangku jabatan Kemlu seperti Vanuatu, Fiji, Papua New Guinea, dan Kepulauan Solomon. Sebagai anggota penuh, Indonesia berpartisipasi dengan memberikan pemecahan masalah dalam forum tersebut, termasuk solusi yang berkaitan Covid-19. Sedangkan pihak ULMWP tidak 
dibolehkan bergabung untuk menyampaikan agenda anggota berstatus pengamat. (Timika Expres, 2021). Setelah melaksanakan SOM, MSG direncakan akan menggelar Foreign Ministers Meeting (FMM) pada 15 hingga 17 Juni 2021 dan dijadwalkan ulang 22 Juni hingga 25 Juni tanpa jaminan bahwa tanggal baru ini tidak akan ditunda lebih lanjut (Asia Pasific Report, 2021).

Forum MSG sering dijadikan wadah bagi sejumlah pihak yang menginginkan Papua merdeka atau menginternasionalisasikan isu Papua sebab penduduk Papua mempunyai ras yang sama dengan penduduk negara-negara anggota MSG (Tampubolon \& Tjarsono, 2015).

Internasionalisasi isu Papua Barat telah menjadi perhatian Indonesia di kawasan Pasifik Selatan, terutama sejak masa pemerintahan Presiden Jokowi. Kekhawatiran yang berkembang ini bukan hanya karena pernyataan yang dibuat oleh negara-negara Pasifik Selatan di forum internasional tetapi juga disebabkan oleh beredarnya berita dan foto tentang pelanggaran HAM di Papua Barat. Penggunaan media sosial telah menjadi alat utama bagi para aktivis prokemerdekaan Papua dan aktor-aktor baru dalam menyuarakan isu Papua Barat. Akibatnya, publik dan pejabat pemerintah di negara-negara Pasifik Selatan seperti PNG, Fiji, dan Vanuatu juga terpengaruh oleh penyebaran informasi di media sosial. Serangkaian dukungan dari demonstrasi, seni mural, dan pernyataan dari pejabat pemerintah telah ditunjukkan oleh penduduk Kepulauan Pasifik kepada masyarakat Papua (Lantang \& Tambunan, 2020).

Nainggolan (2014) dalam penelitiannya menjelaskan bahwa aktivitas gerakan separatis Papua berupaya memanfaatkan momentum yang ada untuk memperjuangkan aspirasi dan kepentingan kelompok separatis dalam rangka mendapatkan dukungan politik dari masyarakat global untuk kemerdekaan Papua. Selain membuka kantor-kantor perwakilan perjuangan di beberapa negara, gerakan separatis Papua juga melakukan kampanye lewat media sosial dan melakukan negosiasi dan mempengaruhi forum-forum internasional.

Amran (2017) mengemukakan bahwa isu negatif tentang Papua yang diusung ke ranah internasional terbagi dalam empat kategori isu utama, yaitu (1) Ekonomi berkaitan dengan aneksasi dan pendayagunaan potensi dan aset ekonomi Papua oleh orang yang bukan bukan berasal dari Papua (non-Papua); (2) Politik berkaitan dengan asal-usul pembauran dan jati diri politik Papua; (3) Keamanan berkaitan dengan sejumlah peristiwa pelanggaran HAM berat dan siklus kekejaman politik; dan (4) Budaya berkaitan dengan segregasi budaya dan ras antara Indonesianisasi dengan Papuanisasi.

Rogers dan storey (1987) dalam (Venus, 2004), menginterpretasikan kampanye sebagai gabungan kegiatan komunikasi yang dipersiapkan sebelumnya, hal ini bertujuan untuk menciptakan dampak tertentu pada publik dan dilakukan dengan berkesinambungan dalam jangka waktu tertentu. Kampanye pada dasarnya merupakan salah satu contoh tindakan persuasi, semua kegiatan dalam kampanye didasari oleh asas mendorong dan mengajak publik agar sukarela menerima atau mau melakukan sesuatu yang direkomendasikan.

Menurut Charles U. Larson (1992), dalam (Venus, 2004), jenis kampanye terbagi menjadi tiga kategori. Pertama, social change campaigns atau dikenal juga dengan ideologically or cause oriented campaigns, yaitu kampanye yang dilakukan dalam rangka mengatasi persoalan sosial 
melalui perubahan perilaku dan sikap publik yang menjadi sasaran, seperti kampanye kemanusiaan, kampanye ekonomi, kampanye lingkungan, kampanye pendidikan, atau kampanye kesehatan. Kedua, Political campaigns atau dikenal juga dengan istilah candidate oriented campaigns. Kampannye ini ditujukan untuk mendapatkan dukungan dari masyarakat terhadap para kontestan yang diusung partai politik agar mampu memenangkan suatu gelaran pemilihan umum yang pada akhirnya dapat menduduki jabatan-jabatan politik tertentu. Ketiga, Commercial campaign atau juga dikenal dengan istilah product oriented campaigns. Kampanye jenis ini umumnya dilakukan di lingkungan bisnis dengan mempromosikan suatu barang atau jasa dan meningkatkan penjualan untuk memperoleh laba.

Selain jenis kampanye, terdapat juga model-model kampanye yang dibagi menjadi enam model. (1) model kampanye Nowak dan Warneryd yang didalamnya terdapat tujuh komponen kampanye yang patut menjadi perhatian dan saling berhubungan, yakni efek yang hendak dicapai, gangguan kampanye, objek kampanye, target kampanye, saluran kampanye, pesan kampanye, dan pihak yang menyampaikan kampanye. (2) The Five Functional Stages Development Model, ada lima tahap dalam model ini meliputi identifikasi, pengesahan atau legalitas, keikutsertaan, penetrasi, dan diseminasi. Fokus model ini berada pada tahapan kegiatan kampanye bukan pada pertukaran pesan. (3) model Kampanye Ostergaard. Suatu rancangan program kampanye untuk perubahan sosial harus dibantu dengan identifikasi masalah dan temuan ilmiah agar berdampak pada penanganan masalah sosial. (4) The Diffusion of Innovations Model, umumnya model ini diaplikasikan pada kampanye yang mengarah pada perubahan sosial dan periklanan. Ada empat tahapan yang akan terjadi selagi proses kampanye ini berjalan, dimulai dari tahap informasi, kemudian persuasi, lalu membuat keputusan mencoba, hingga konfirmasi atau reevaluasi. (5) model komponensial kampanye, Komponen kampanye berupa efek dan umpan balik, pesan, saluran, sumber kampanye, penerima kampanye, digunakan pada model kampanye ini. Model ini lebih mudah dikenal dengan menggunakan pendekatan transmisi daripada pendekatan interaksi karena kampanye adalah kegiatan komunikasi yang terencana, memiliki tujuan, dan sedikit memiliki potensi untuk saling bertukar informasi dengan publik. (6) The Communicative Functions Model. Model ini diaplikasikan pada jenis political campaigns yang berkaitan dengan para kandidat partai politik (Venus, 2004).

Penggunaan media sosial dalam kampanye merupakan pilihan yang tepat, hal ini disebabkan media sosial dinilai efektif mengingat cirinya yang mudah diakses dimanapun dan kapan saja. Media sosial juga dapat mendistribusi informasi dalam waktu singkat kepada publik (Ulfa \& Fatchiya, 2018). ULMWP melakukan kampanye di media sosial melalui jejaring media sosialnya, seperti akun Twitter @FreeWestPapua dan akun Facebook Free West Papua.

Penelitian tentang jejaring media sosial Free West Papua Campaign sudah dilakukan sebelumnya dengan menelaah cara konsumsi teks menggunakan data dari respons para pembaca berita dalam bentuk retweet, quote retweet, comment, dan like, via akun Twitter @FreeWestPapua dan @BennyWenda serta halaman Facebook Free West Papua Campaign (Rumila \& Effendi, 2020). Penelitian lainnya yaitu penelitian tentang akun Facebook Free West 
Papua. Martadikusumah, (2019) meneliti tentang penggunaan media propaganda kemerdekaan Papua Barat berupa akun Facebook Free West Papua.

Penelitian lain menjelaskan bahwa dalam kasus perang asimetris antara Free West Papua Campaign (FWPC) dan Indonesia, FWPC menggunakan musik dan lagu sebagai senjata untuk melawan Indonesia. Senjata itu tidak ditujukan langsung ke Indonesia tetapi ditujukan kepada masyarakat internasional melalui media sosial sehingga pemerintah Indonesia akan bereaksi terhadap masyarakat internasional (Jahamou \& Wiswayana, 2020).

Berdasarkan berbagai penelitian diatas, tidak ada penelitian secara spesifik tentang kampanye akun Twitter @FreeWestPapua yang dikaitkan dengan MSG dan ULMWP. Untuk itu, kebaruan penelitian ini berkaitan dengan kampanye akun Twitter @FreeWestPapua dalam mendukung ULMWP tergabung di MSG. Penulis memilih akun @FreeWestPapua karena dalam penelitian Fahmi (2019), alat analisis media sosial berupa Drone Emprit menunjukkan bahwa akun@FreeWestPapua merupakan top influencer (pemengaruh teratas) terkait isu Papua. Dengan demikian, tulisan ini bertujuan untuk mengetahui bagaimana kampanye yang dilakukan oleh akun Twitter @FreeWestPapua terkait dukungan ULMWP tergabung dalam MSG dan bagaimana respons pengguna Twitter lainnya terhadap kampanye tersebut.

\section{Metode Penelitian}

Penulis menggunakan penelitian kualitatif sebagai pendekatan dalam penelitian ini. Proses penelitian kualitatif diawali dengan memilih proyek penelitian. Selanjutnya mengutarakan sejumlah pertanyaan yang terkait dengan proyek penelitian, kemudian menghimpun data yang berhubungan dengan sejumlah pertanyaan dimaksud sebelumnya, mengatur catatan data yang sudah dihimpun, dan menganalisisnya. Penelitian kualitatif bersifat terbuka terhadap peluang melakukan desain ulang, serta akumulasi dan analisis data berjalan serentak. Teknik analisis data difokuskan untuk memberikan jawaban terhadap pertanyaan penelitian atau menguji hipotesis yang telah disusun sebelumnya (Hardani, dkk, 2020). Dalam penelitian ini, penulis menggunakan data dari akun Twitter @FreeWestPapua dan situs web freewestpapua.org. Data tersebut kemudian disandingkan dengan penelitian sebelumnya dan teori-teori yang ada.

\section{Hasil dan Pembahasan}

\subsection{Kampanye di Ruang Siber}

Dalam rangka memperoleh dukungan agar ULMWP menjadi anggota penuh dalam MSG, Free West Papua Campaign melalui akun Twitternya, yakni @FreeWestPapua. Akun ini memiliki pengikut (Followers) sebanyak 68,1 ribu dan mengikuti sebanyak 6.845 akun Twitter. 


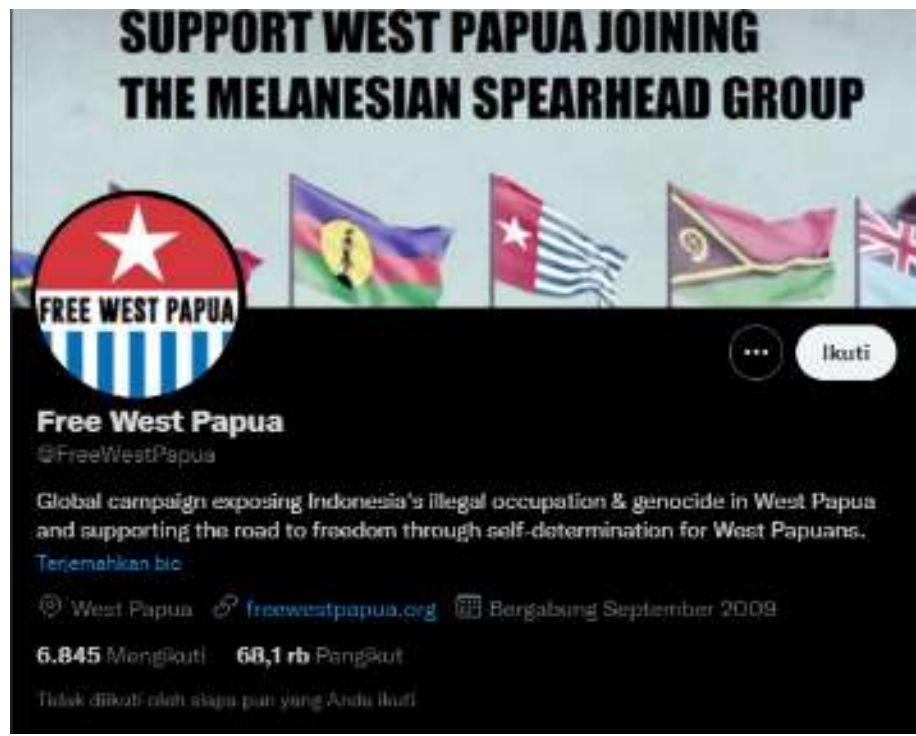

Sumber: https://twitter.com/FreeWestPapua

Gambar 1. Tangkapan layar beranda akun @FreeWestPapua

Akun@FreeWestPapua melakukan kampanye di media sosial Twitter dengan mengajak pengikutnya (warganet) untuk bergabung dalam suara global sebagai bentuk solidaritas mendukung keanggotaan penuh ULMWP dalam MSG. Kampanye tersebut diunggah dalam bentuk narasi yang disertai dengan foto dan tautan yang mengarahkan warganet ke situs web freewestpapua.org. Gambar 2 menunjukkan tangkapan layar unggahan akun @FreeWestPapua tentang ajakan mendukung ULMWP menjadi anggota penuh MSG

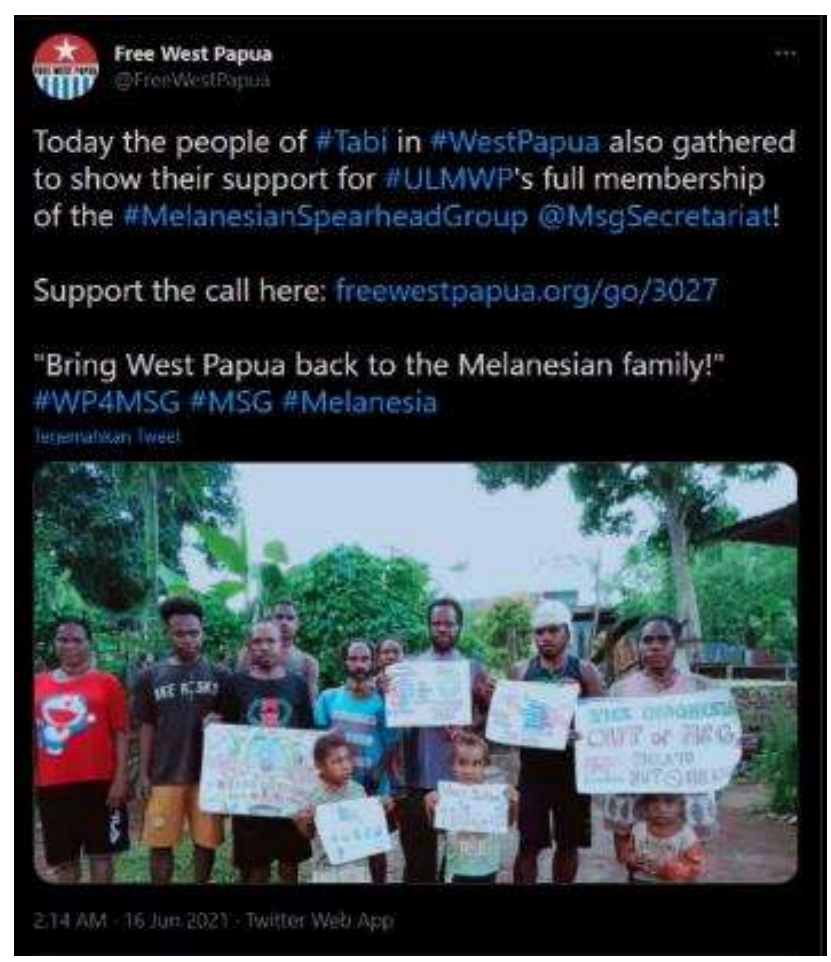

Sumber: https://twitter.com/FreeWestPapua/status/1404880046796554246

Gambar 2. Tangkapan Layar Unggahan Akun @FreeWestPapua 
Melalui unggahan tersebut, penulis kemudian menelusuri tautan yang disertakan dan hasilnya yaitu kampanye yang dimuat dalam situs web freewestpapua.org mengajak warganet agar memanfaatkan momentum rencana pertemuan pimpinan negara-negara Melanesia. Pemanfaatan itu dalam bentuk dukungan terhadap keanggotaan penuh ULMWP dalam MSG.



Join our global voice in solidarity for West Papua's full MSG membership

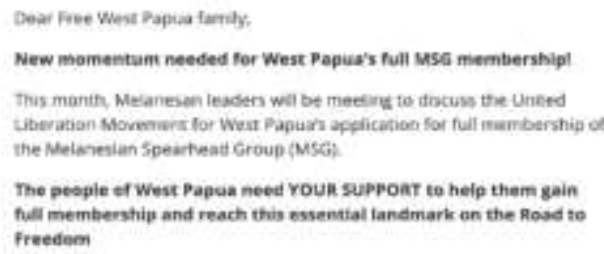

The pespie ef West Papca need Youll suppoat to help them gain fill membership and reach this sessenttal landmark on the Road to Freeder

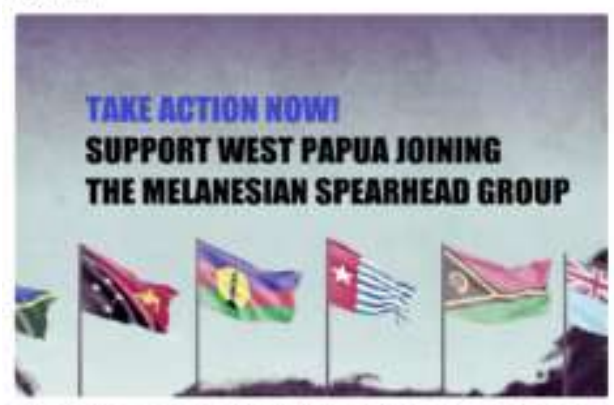

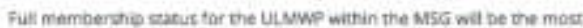

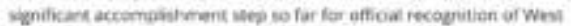
Papians as a Mecanesian people; a desigration that officilly chalenges.

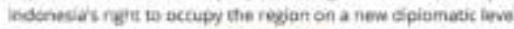
Flease gro nere hor mare infocmation on Mesc, vinwP and West papue

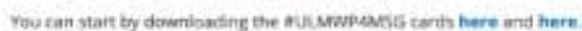
Send us rover photes of yos holding trien and stiveing your support and wo weli ohere your ieliderily on our secial medie te rabe mort awareness and momentum aroond the M5G.


We heed our global voices to conse mgether again in zonge is acts af


Papurs tull memberstip is the MSG,
Lets jan our voices and spirta and come togedver in solidarity and love for the United Uberation Mtvement for West Papur's application to the Mse



Hey Wantok: A song for West Papua to join the MSG

This sang was conosied by the pecple of Weut Papua for thet Velanes an wantoks and hrothers and sisters as a cry for heip to suppon sher famaies left behind in Wegs Papua s cats for Weat Papuas fult. membership of the Meianesian Soeartiead Group ovsial:

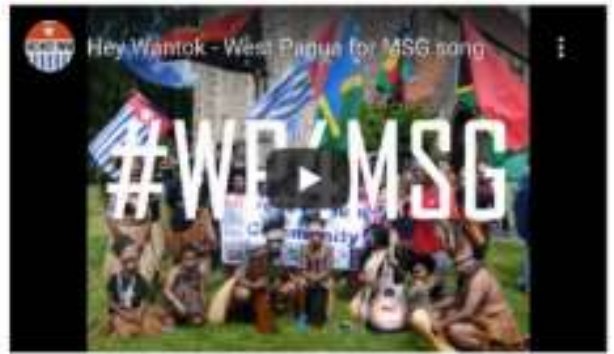

P. EKGE he'g is to soned this song around the wand so everyone car share in ve spirt o/ West Plapualt you can find the nurds below Here is other ways how you can join us:

-jein Kize of the Merming Star, a collective of musicians dedicating to raising awareness and support for West Papurs freedom and full MSG membership!.

- Upioad as many photos and messages of oupport as possibie an your Facebook, twitter and lestagram accounts using the hashtags below.

- Make it your profile photo and ask all of your friends and family to do the same.

- Send all photos and vides mesuges of support to the Free West Papua Campaign Facebeok Page \& Nize of the Morning Stan.

Your phatss wit be posted tar everyone in see

PifAst use the hathag and mosseges beiow.

eulmwoanse

WPaMse

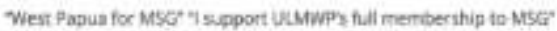

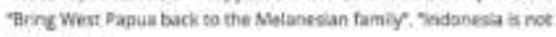
Melonesian

We believe the MSG stands as a beacan of hope for all who struggie for sels-determination and independence.

We believe we will become full members of the MSGG and come home to our Melanesian family.

We need to come together again and show solidarity to the ULMWP now and support their call for full membenhip to the MSG.

bin us for the results s $\frac{a}{2}$ follow all proeress on our farebopk.

Sumber: https://www.freewestpapua.org/actions/wp4msg/

Gambar 3. Tangkapan Layar Kampanye Dukungan Keanggotaan Penuh ULMWP pada MSG 
Merujuk pada penelitian Nainggolan (2014) yang menyatakan bahwa gerakan separatis Papua berupaya memanfaatkan momentum yang ada untuk menyampaikan keinginannya, kampanye dalam situs web freewestpapua.org telah memanfaatkan momentum rangkaian kegiatan MSG khususnya menjelang pelaksanaan MSG Leaders' Summit (KTT), meskipun hingga saat ini kelanjutan KTT tersebut belum ada kejelasan karena adanya penundaan.

Kempanye tersebut berupaya menginternasionalisasikan isu tentang Papua. Sesuai dengan penelitian Amran (2017), isu utama yang disampaikan pada kampanye tersebut didominasi isu politik yang ditandai dengan upaya pencairan dukungan internasional tentang ULMWP dijadikan sebagai anggota penuh dalam MSG. Selain itu, isu lain yang digunakan adalah isu budaya. Hal itu ditunjukkan dengan narasi kampanye yang menyatakan bahwa ULMWP akan menjadi anggota penuh MSG dan kembali ke keluarga Melanesia. Penulis menilai, narasi tersebut mengindikasikan bahwa kampanye mengangkat isu tentang diskriminasi ras yang menganggap bahwa ras Indonesia berbeda dengan ras papua karena ras Papua adalah ras Melanesia. Sedangkan isu lainnya seperti isu keamanan dan ekonomi tidak ditemukan dalam kampanye tersebut.

Hasil penelitian ini mendukung penelitian dari Jahamou dan Wiswayama (2019) yang menjadikan lagu dan musik sebagai senjata untuk menginternasionalisasikan isu Papua. Hal itu dibuktikan dengan narasi kampanye yang menyertakan lagu khusus, yakni "Hey Wantok: A song for West Papua to join the MSG"

Jika ditinjau dari jenis kampanye, kampanye yang dilakukan oleh Free West Papua Campaign masuk dalam kategori jenis kampanye Ideologically or cause oriented campaigns atau juga dikenal dengan nama social change campaigns. Hal ini dikarenakan kampanye yang dilakukan cenderung berupaya merubah sikap dan perilaku publik untuk mau bergabung dalam kampanye mendukung ULMWP menjadi anggota penuh MSG.

Berdasarkan sejumlah model kampanye yang disajikan, penulis menilai model kampanye yang digunakan oleh Free West Papua Campaign adalah model komponensial kampanye. Komponen pada kampanye ini yaitu sumber kampanye, saluran, pesan, penerima kampanye, efek dan umpan balik. Rinciannya yaitu (1) Sumber kampanye berasal dari organisasi sukarelawan bentukan Benny Wenda, yakni Free West Papua Campaign melalui akun media sosial Twitter @FreeWestPapua dan situs web freewestpapua.org. (2) Saluran yang digunakan adalah ruang siber, terutama media sosial Twitter dan media daring berupa situs web. (3) Pesan yang disampaikan adalah permintaan dukungan agar ULMWP menjadi anggota penuh MSG. (4) Penerima kampanye kepada warganet dari berbagai negara, termasuk akun-akun pengikut akun Twitter @FreeWestPapua. (5) Efek dan umpan balik berupa unggahan foto dan tagar sesuai dengan instruksi kampanye.

\subsection{Respons Kampanye Akun @FreeWestPapua di Twitter}

Dalam menentukan respons dari kampanye akun @FreeWestPapua, penulis fokus pada instruksi dari kampanye tentang penggunaan tagar dan pesan seperti West Papua for MSG, I 
support ULMWP's full membership to MSG, Bring West Papua back to the Melanesian family, Indonesia is not Melanesian, \#ULMWP4MSG dan \#WP4MSG.

Merujuk pada teori kampanye, tampak jelas bahwa kampanye yang diunggah pada situs web freewestpapua.org merupakan bentuk komunikasi yang telah dipersiapkan sebelumya dengan tujuan menghasilkan dampak tertentu pada publik. Dalam hal ini efek yang yang diciptakan berupa mengunggah foto dengan menggunakan tagar sesuai dengan instruksi kampanye, seperti yang diunggah oleh salah satu akun Twitter, yakni akun @khirlani, mengikuti instruksi tentang penggunaan \#WP4MSG kemudian disertakan narasi terkait dukungan dari warga di Sentani, Provinsi Papua. Gambar 4 menunjukkan tangkapan layar unggahan akun @khirlani yang mengunggah foto dan tagar sesuai instruksi kampanye di situs web freewestpapua.org.

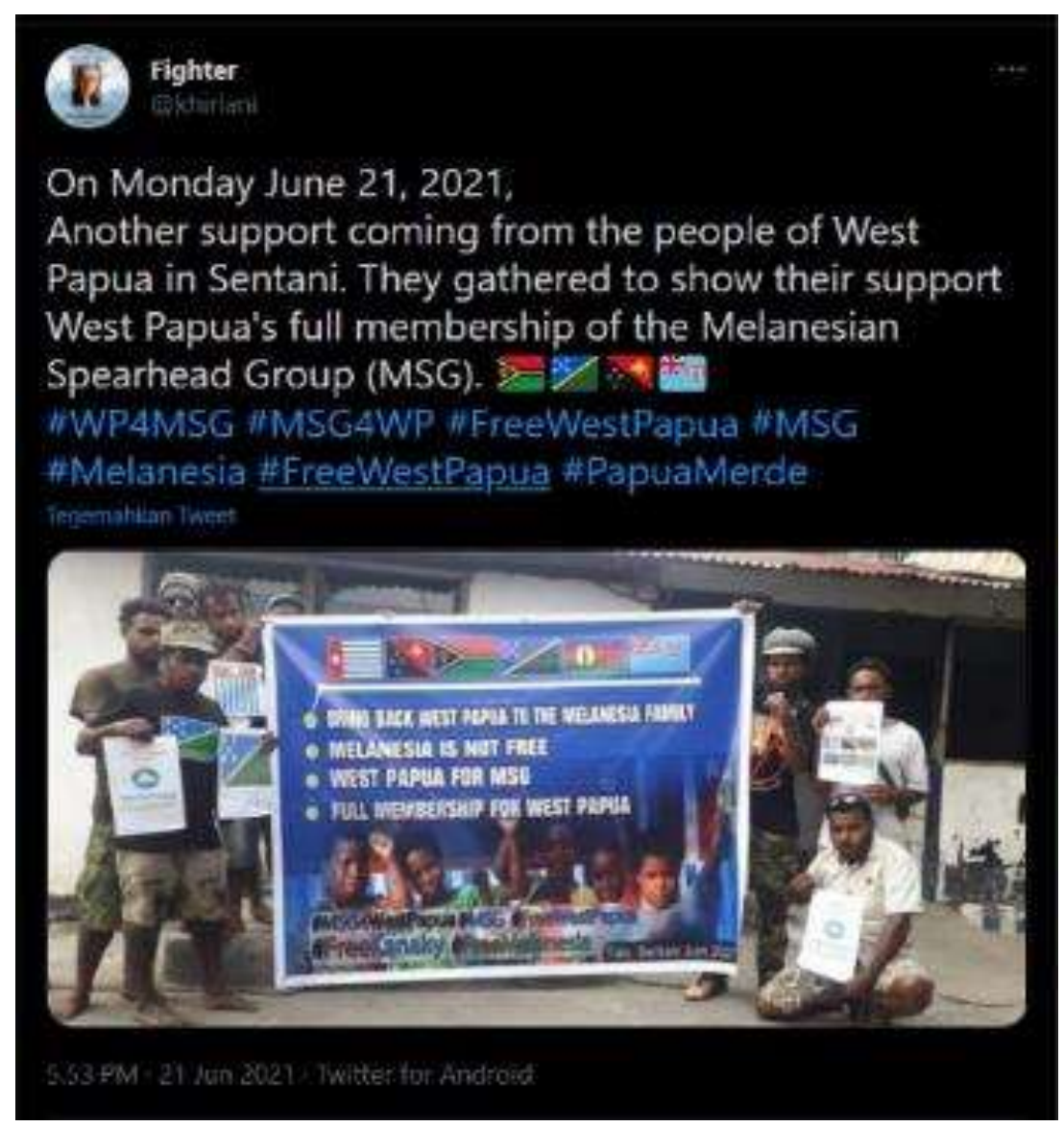

Sumber: https://twitter.com/khirlani/status/1406928158775934981

Gambar 4 Tangkapan Layar Unggahan Akun @khirlani

Selain itu, respons lain juga ditunjukkan oleh akun @PantauPapua dengan mengunggah foto disertai dengan tagar \#ULMWP4MSG dan \#WP4MSG kemudian ditambahkan narasi untuk mengajak pengguna Twitter lainnya untuk memberi dukungan terhadap keanggotaan penuh Papua Barat dalam MSG. Gambar 5 menunjukkan Tangkapan layar unggahan akun @PantauPapua yang mengunggah tagar sesuai instruksi kampanye di situs web freewestpapua.org. 


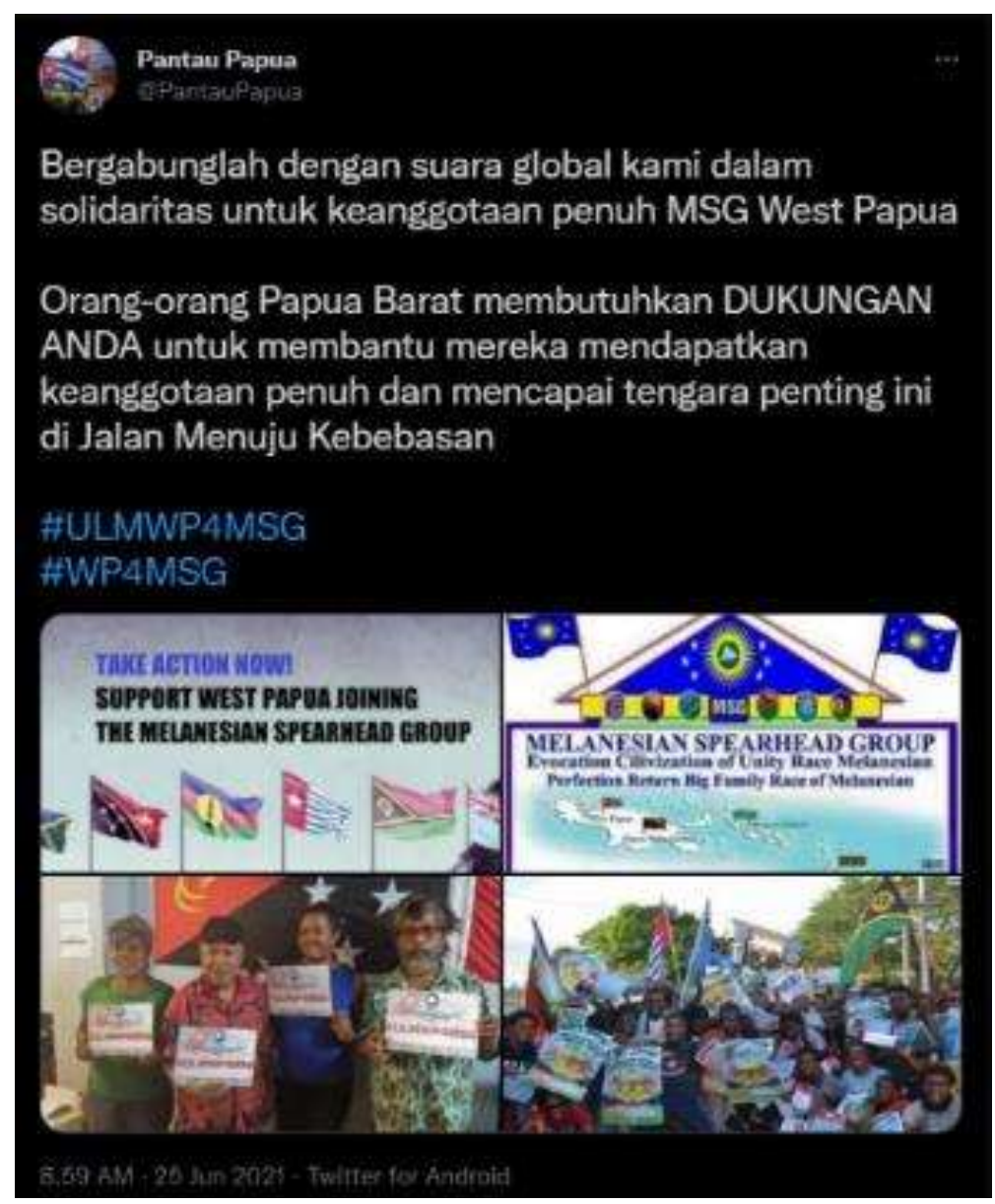

Sumber: https://twitter.com/PantauPapua/status/1408243388789387265

Gambar 5. Tangkapan Layar Unggahan Akun @PantauPapua

Berbeda dengan akun @khirlani dan @PantauPapua, akun ini tidak mengikuti instruksi terkait tagar, tetapi mengikuti instruksi mengenai pesan yang harus diunggah dalam media sosial, yakni "west Papua for MSG" yang dilengkapi dengan narasi mengenai dukungan Papua Barat dikembalikan ke MSG dan dukungan Papua Barat menjadi anggota penuh MSG. Narasi tersebut pada intinya memberikan makna yang sama pada instruksi dari kampanye akun @FreeWestPapua. Gambar 6 menunjukkan tangkapan layar unggahan Akun @wawaw222 yang mengunggah pesan sesuai instruksi kampanye di situs web freewestpapua.org.



Sumber: https://twitter.com/wawaw222/status/1407214429176016898

Gambar 6. Tangkapan Layar Unggahan Akun @wawaw222 
Berdasarkan temuan penulis dalam media sosial Twitter melalui kolom pencarian, tidak semua pengguna Twitter mengikuti instruksi dari kampanye. Instruksi yang paling banyak diikuti adalah instruksi terkait tagar (\#ULMWP4MSG dan \#WP4MSG) kemudian disusul dengan instruksi mengunggah pesan (Indonesia is not Melanesian, Bring West Papua back to the Melanesian family, West Papua for MSG, dan I support ULMWP's full membership to MSG). Namun, dengan catatan bahwa unggahan pesan memang tidak sama persis dengan yang diinstruksikan tetapi masih memiliki makna yang sama dengan instruksi yang ada.

\section{Kesimpulan}

Free West Papua Campaign telah berupaya mencari dukungan dari siapa saja dan dari mana saja agar tujuan untuk menjadikan ULMWP sebagai anggota penuh dalam MSG dapat tercapai. Pencarian dukungan tersebut dilakukan menginternasionalisasikan isu Papua dan melakukan kampanye di ruang siber baik di media sosial maupun di media daring. Selain itu, dalam perspektif teori kampanye, Free West Papua Campaign menggunakan kampanye jenis ideologically or cause oriented campaigns dan menggunakan model kampanye berupa komponensial kampanye. Adapun respons dari pengguna Twitter lebih didominasi mengikuti instruksi tentang tagar daripada pesan yang ingin disampaikan. Penulis hanya fokus pada respons pengguna Twitter padahal kampanye tersebut juga ditujukan untuk pengguna media sosial instagram dan facebook. Untuk itu, peneliti selanjutnya dapat melakukan penelitian lebih komprehensif dengan membandingkan respons dari setiap pengguna media sosial.

\section{Daftar Pustaka}

Amran, K. (2017). Politik Melanesia dan Diplomasi Indonesia (Studi Analisis: Geopolitik dan Geostrategi Separatisme di Papua Pasca Sidang Majelis Umum PBB ke-70). Universitas Sumatera Utara.

Asia Pasific Report. (2021). West Papua Unhappy Over Never-ending MSG Membership Tragedies. https://asiapacificreport.nz/2021/06/21/west-papua-unhappy-over-neverending-msg-membership-tragedies/.

Direktorat Kerja Sama Intrakawasan dan Antarkawasan Asia Pasifik dan Afrika. (2019). Melanesian Spearhead Group (MSG). https://kemlu.go.id/portal/id/read/128/halaman_list_lainnya/melanesian-spearhead-groupmsg.

Fahmi, I. (2019). Tiadanya kontra narasi internasional tentang "West Papua." https://pers.droneemprit.id/tiadanya-kontra-narasi-internasional-tentang-west-papua/

Free West Papua Campaign. (n.d.). Join Our Global Voice in Solidarity for West Papua's full MSG Membership. Retrieved October 21, 2021, from https://www.freewestpapua.org/actions/wp4msg/

Hardani, H. A., Ustiawaty, J., Istiqomah, R. R., Fardani, R. A., Sykmana, D. J., \& Auliya, N. H. (2020). Buku Metode Penelitian Kualitatif dan Kuantitatif (Issue April). CV. Pustaka IImu 
Group.

Jahamou, M., \& Wiswayana, W. (2020). Music as A Weapon on Asymmetric War between FWPC (Free West Papua Campaign) Against Indonesia. In B-Space 2019: Proceeding of the First Brawijaya International Conference on Social and Political Science. https://doi.org/10.4108/eai.26-11-2019.2295195

Lantang, F., \& Tambunan, E. M. B. (2020). The Internationalization of "West Papua" Issue and Its Impact on Indonesia's Policy to the South Pacific Region. Journal of ASEAN Studies, 8(1), 41-59. https://doi.org/10.21512/jas.v8i1.6447

Martadikusumah, T. A. A. (2019). Penggunaan Akun Facebook Free West Papua Campaign sebagai Media Propaganda Konflik Papua Barat. Universitas Katolik Parahyangan.

Nainggolan, P. P. (2014). International Activities of Papua Separatist Movement. Jurnal Kajian, Volume 19(No.3), 181-199.

Pemerintah Provinsi Papua. (n.d.). Sekilas Papua. Retrieved October 21, 2021, from https://papua.go.id/view-detail-page-254/Sekilas-Papua-.html.

Ramadhan, F. Z. (2018). Improvement of the Status of Indonesia To Become Associate Member of Melanesian Spearhead Group (MSG). Universitas Jember.

Rumila, D. N., \& Effendi, Y. (2020). Analisis Wacana Free West Papua Campaign pada Operasi Militer Indonesia dalam Konflik Nduga: Sebuah Tinjauan Kritis. Transformasi Global, 7(1), 27-42. https://doi.org/10.21776/ub.jtg.2020.007.01.2

Samosir, H. A. (2016). MSG Tolak Keanggotaan Gerakan Pembebasan Papua. CNN Indonesia. https://www.cnnindonesia.com/internasional/20160714193455-106-144820/msg-tolakkeanggotaan-gerakan-pembebasan-papua

Tampubolon, L. K., \& Tjarsono, I. (2015). Kerjasama teknik indonesia indonesia 士. JOM FISIP, 2(2). https://media.neliti.com/media/publications/32844-ID-kerjasama-teknik-indonesiaindonesia-melanesian-spearhead-group-terhadap-keutuha.pdf

Timika Expres. (2021). Organisasi MSG Fokus Pemulihan Ekonomi Pasca Covid-19. https://timikaexpres.com/index.php/2021/05/07/organisasi-msg-fokus-pemulihan-ekonomipasca-covid-19/.

Ulfa, G. S., \& Fatchiya, A. (2018). Efektivitas Instagram "Earth Hour Bogor" sebagai Media Kampanye Lingkungan. Jurnal Komunikasi Pembangunan, 16(1), 144-157. https://doi.org/10.29244/jurnalkmp.16.1.144-157

Venus, A. (2004). Manajemen Kampanye: Panduan Teoretis dan Praktis dalam Mengefektifkan Kampanye Komunikas. Simbiosa Rekatama Media. 